ANL / CP -72828

DE92 004147

\title{
THERMAL RESPONSE OF SUBSTRATE STRUCTURAL MATERIALS DURING A PLASMA DISRUPTION*
}

\author{
by \\ Ahmed Hassanein and Dale L. Smith \\ Argonne National Laboratory \\ Fusion Power Program \\ 9700 South Cass Avenue \\ Argonne, Illinois 60439 USA
}

\section{DISCLAIMER}

\begin{abstract}
This report was prepared as an account of work sponsored by an agency of the United States Government. Neither the United States Government nor any agency thereof, nor any of their employees, makes any warranty, express or implied, or assumes any legal liability or responsibility for the accuracy, completeness, or usefulness of any information, apparatus, product, or process disclosed, wi represents that its use would not infringe privately owned rights. Reference herein to any specific commercial product, process, or service by trade name, trademark, manufacturer, or otherwise does not necessarily constitute or imply its endorsement, recommendation, or favoring by the United States Government or any agency thereof. The views and opinions of authors expressed berein do not necessarily state or reflect those of the United States Government or any agency thereof.
\end{abstract}

* Work supported by the Office of Fusion Energy, U.S. Department of Energy under Contract Number $W-3^{*}-109$-Eng-38.

Submitted to the Fifth International Conference on Fusion Reactor Materials, Clearwater, Florida, November 17-22, 1991. 


\section{THERMAL RESPONSE OE SUBSTRATE STRUCTURAL MATERIALS DURING A PLASMA DISRUPTION \\ Ahmed Hassanein and Dale L. Smith \\ Argonne National Laboratory \\ Fusion Power Program \\ 9700 South Cass Avenue \\ Argonne, IL 60439 USA}

\section{Abstract}

Intense energy fluxes to in-vessel components like the first wall and the divertor plate of a fusion reactcr are expected during plasma disruptions. This high energy deposition in shurt times may cause severe surface erosicn of these components resulting from melting and vaporization. Coatings and tile materials are proposed to protect and maintain the integrity of the underneath structural materials from both erosion losses as well as from high thermal stresses encountered during a disruption. The coating thickness should be large enough to withstand both erosion losses and to reduce the temperature rise in the substrate structural material. Yet the coating thickness should be minimized to reduce potential problems from raoioactivity, toxicity, and plasma contamination.

Tile materials such as graphite and coating materials such as tungsten and beryllium on structural materials like copper and steel are analyzed as potential divertor and first wall design options. The disruption is assumed to be composed of two phases: a thermal quench phase followed by a surrent quench phase. The minimum coating thickness required to protect the structural material is discussed for a range of disruption parameters. 


\section{Introduction}

High energy fluxes on the plasma chamber wall, divertor plates, and other components of a magnetic fusion reactor are expected during plasma disruptions. The energy dump on such components may exceed 1 GJ with a deposition time estimated to be in the ms range or shorter. Such high energy fluxes can cause severe surface erosion of these components from sirface melting and vaporization. Coatings and tile materials are proposed as sacrificial layers to protect and maintain the integrity of the underneath structural materials. Not only to protect the structural materials from the severe expected erosion but also from the high thermal stresses and temperatures encountered during the disruption which can deteriorate the fatigue lifetime of these vital components.

Because of the current understanding of the severity of the disruption event and the total number of disruptions expected during the reactor lifetime, it is difficult to find a coating material with a reasonable initial thickness that can last the entire reactor lifetime. Therefore, it is proposed for a device like ITER for example to cover the structural material of the first wall by a thin layer of a coating material like tungsten or beryllium. This thin layer may have to be continuously replenished by plasma spraying techniques or other methods every several disruptions to keep maintaining the integrity of the first wall. By doing this it is much easier to replace the coating material than to replace the structural material which may require extensive repair and long reactor down time.

The coating thickness should be large enough to withstand and resist both erosion losses and to reduce the temperature rise in the substrate structure. On the other hand the coating thickness should be minimized to 
reduce potential problems such as radioactivity, toxicity, and plasma contamination.

Other design options call for the use of carbon based materials as tiles over the structural materials for protection. It is difficult however to continuously replenish the eroded carbon material from sputtering and disruption erosion by similar techniques available for metals. It is then required that the initial tile thickness be sufficient enough to protect the structure both at the beginning-of-life (BOL) and near the end-of-life (EOL) operation. The conditions on the substrate is expected to be harsh near the end-of-life since the tile thickness will be eroded to its minimum and its material properties, especially the thermal conductivity, will be quite degraded by the neutron irradiation. Both thin thickness and lower thermal conductivity of the tile tend to increase the temperature $r$ ise in the substrate during disruptions.

\section{Design options and parameters}

Two design options are considered in this analysis. One design option is for the first wall which uses a thin (a fraction of a millimeter) coating of tungsten or beryllium over 2 centimeters of stainless steel as the structural wall material. The second design option is for the divertor plate which uses a 1 centimeter thick carbon-fiber-composite (CFC) as a tile material over 3 millimeters of copper alloy as the heat sink structure. The CEC used in this analysis is the $\mathrm{CX}-2002 \mathrm{U}$ composite which is currently available commercially. Near the end-of-life analysis assumes the thickness of the CEC to be eroded down to 3 millimeters, with a thermal conductivity similar to that of the irradiated SEPCARB. 
The disruption scenario is composed of two phases. A thermal quench phase followed by a current quench phase. The duration of the thermal quench phase is usually short and it ranges from $0.1 \mathrm{~ms}$ up to $3.0 \mathrm{~ms}$. The duration of the current quench phase is in the order of 10-50 ms. The energy densities deposited during the disruption considered in this analysis are typical of those for ITER design. During the thermal quench phase it is assumed that 2 $\mathrm{MJ} / \mathrm{m}^{2}$ is deposited on the first wall and $12 \mathrm{MJ} / \mathrm{m}^{2}$ is deposited on the divertor plate. In the current quench phase, $2 \mathrm{MJ} / \mathrm{m}^{2}$ is assumed deposited on both the first wall and the divertor plate.

The analysis presented in this paper is mainly devoted to study the response of the substrate structural material to the combined two phase disruption. The response of the tile and the coating materials to disruptions has been analyzed in detail elsewhere [1-3]. The requirements for the coating and the tile thicknesses to maintain the thermal integrity of the substrate are investigated for various design options and disruption parameters.

\section{Thermal analysis}

The computer code A*THERMAL-2 [4] is used in this study to calculate the thermal response of the substrate structure during a disruption. The code uses advanced numerical methods in both finite difference and finite element techniques to solve highly non-linear heat conduction problems in one or two dimension. Up to four consecutive layers of different tile and structural materials can be analyzed in one design. Moving boundaries and phase change as well as other boundary conditions can be used for any layer of the structure. The heat source to the material can be energetic ions, electrons, $x$-rays, laser or surface heat flux, or a combination of these sources. 
The heat load on the material can be a steady, a transient, or a moving load across the surface.

The analysis of the first wall design case is described below. Fig. 1 shows the stainless steel substrate surface temperature for different thermal quench times followed by a $20 \mathrm{~ms}$ current quench disruption. The disruption energy is assumed to be $2 \mathrm{MJ} / \mathrm{m}^{2}$ for both the thermal and the current disruption phases. The coating material is tungsten with a thickness of 0.3 $\mathrm{mm}$. It is interesting to see that the lowest substrate surface temperature results from the shortest thermal quench time, i.e. $0.1 \mathrm{~ms}$, and the highest surface temperature is due to the $1.0 \mathrm{~ms}$ thermal quench contrary to the response of the tile or the coating material [1]. This can be explained by the following. Shorter disruption times usually results in the highest surface temperature of the coating or the tile material that are directly exposed to the disruption. This means more erosion of the coating or the tile material. Consequently a larger fraction of the incident energy is spent in vaporizing the surface material, leaving less fraction of the energy to be conducted through the tile to the substrate material, which causes lower temperature rise. !' Longer disruption times, however, result in lower temperatures throughout the tile and the substrate materials. It can also be seen from Fig. 1 that the stainless steel surface temperature will exceed its melting point $(1700 \mathrm{~K})$ for the cases of $1.0 \mathrm{~ms}$ and $3.0 \mathrm{~ms}$ thermal disruption time. This means the $0.3 \mathrm{~mm}$ tungsten coating thickness is not sufficient to protect the substrate structure. In addition to the resulting high thermal the stresses, repeated melting and solidification of the interface between the coating and the substrate may develop cracks and gaps which tend to di ive the temperature even higher. 
Figure 2 shows the substrate surface temperature for the same conditions as for Fig. 1 but for a tungsten coating of $0.5 \mathrm{~mm}$ thickness. No melting of the steel substrate is predicted in this case for any of the thermal disruption times considered. In general thicker coating materials offer better protection to the substrate structural material. The effect of different current disruption times on the substrate surface temperatire after $1.0 \mathrm{~ms}$ thermal quench is shown in Fig. 3. Shorter current quench deposition times will probably always result in higher substrate temperature contrary to the thermal quench times. This is true mainly because the current quench time is usually much longer than the thermal quench time. Longer disruption times allow less energy to go toward eroding the coating or the tile material and more energy in conduction through the substrate material. For example at $1 \mathrm{~ms}$ thermal quench followed by a shorter $10 \mathrm{~ms}$ current quench of $10 \mathrm{~ms}$, the tungsten coating will have to be thicker than $0.5 \mathrm{~mm}$ to prevent the steel substrate from melting.

The current quench effect on the substrate material is usually tolerable for these disruption energies. It is, however, when immediately follow the thermal quench phase that can cause higher substrate surface temperatures. Fig. 4 shows the response of the substrate to a separate thermal and a separate current quench as well as to a combined thermal and current disruptions. For locations where the two disruptions do not overlap, the substrate temperature does not exceed the melting temperature even for a 0.3 mm thick tungsten coating.

The effect of using beryllium coating versus tungsten coating with the same thickness over stainless steel substrate is shown in Fig. 5. Beryllium coating substantially reduces the substrate temperature $r$ ise during the disruption compared to tungsten. Thus offers better protection to the 
substrate for the same coating thickness and disruption parameters. The main reason is that beryllium is less resistant to the disruption than tungsten. Which means that more disruption energy will be spent in eroding beryllium than tungsten, leaving less energy to be conducted through the substrate. The better protection to the substrate is then on the expense of more beryllium erosion than tungsten. For example in the case of $1.0 \mathrm{~ms}$ thermal quench followed by $10 \mathrm{~ms}$ current quench, beryllium erosion is substantially more than turgsten erosion at these energy densities. These disruption conditions happen to be less than the threshold required for any significant tungsten vaporization. Recoating by plasma spraying or other techniques will then be more frequent in the case of beryllium. In addition, the cost of cleaning the redeposited material after disruptions, safety considerations, and potential plasma contamination may be higher for the beryllium case.

The analysis for the divertor design option, where a CFC tile is used on a $3 \mathrm{~mm}$ copper substrate, is described below. It is expected that the most severe conditions on the copper substrate will be near the end-of-life, where the tile thickness is eroded to its minimum and has suffered extensive radiation damage to its properties. The response of the tile material to a two-phase disruption scenario is shown in Fig. 6. Shorter thermal disruption times will always result in the highest tile surface temperature rise and usually the highest erosion rate. There are two factors that effect the response of the tile at $B O L$ and at EOL to a disruption. The first factor is that at BOL where the tile initial thickness is much larger, the tile surface temperature prior to a disruption is higher. This tends to increase the tile erosion rate at $80 \mathrm{~L}$. The second factor is that at EOL the tile thermal conductivity is lower because of the irradiation damage. This slightly tends 
to increase the erosion rate at EOL. The overall tile erosion rate at $\mathrm{BOL}$ and EOL is somewhat similar for the same disruption conditions.

The copper substrate surface temperature rise at EOL for different thermal quench times is shown in Fig. 7. The shorter the thermal quench, the lower the copper surface temperature. This is again because shorter thermal quench times result in the highest tile erosion rate leaving less energy to be conducted through the tile and the substrate material. The maximum copper surface temperature is less than $900 \mathrm{~K}$ for a duration of less than one second as a result of this disruption parameters. However, smaller tile thicknesses than $3 \mathrm{~mm}$ and higher disruption energies will result in an unacceptable higher substrate temperature and may cause irreversible damage to the structure.

Figure 8 compares the substrate surface temperature at BOL and at EOL. It can be seen that at $\mathrm{BOL}$ the temperature rise is much lower and occurs later in time than that at EOL. It is then important when designing a system like this to take into considerations all the expected conditions near the end-oflife. This should include the allowed minimum tile thickness, its degraded conductivity, the disruption scenario, and the deposited energy densities. There are other important factors that may affect the performance of both the coating/tile materials and the substrate structural materials. One important factor is the vapor shielding effect i.e. the shielding of the surface material by its own vapor against the plasma particles. A comprehensive model of the dynamic interaction of the incident plasma particles with the evaporated wall material is bein, developed [5]. Vapor shielding may protect both the surace and the substrate materials by reducing the amount of energy that reaches the surface material during a disruption. Vapor shielding is believed to be more effective at higher incident plasma energy deposited in very short times. A second important factor is the 
stability of the melt layer developed at the surface of a metallic coating during a disruption [6]. Erosion due to melt layer run-off or due to developed instabilities will cause substantial damage to both the coating and the substrate materials. Melt layer run-off and loss due to growing instabilities are particularly important at longer deposition times specifically during current quench phases [7]. Another important factor is the condition of the plasma sprayed metallic material needed to replenish the eroded material. Porous sprayed materials with loher thermal conductivity can result in higher substrate temperature rise. However, for more severe disruptions, i.e. higher energies deposited in shorter disruption times, porous surface materials are found to protect the substrate more than the original material. This is because the porous coating will suffer more erosion due to tise higher temperature thus leaving smaller a fraction of the incident energy to be conducted through the substrate.

\section{Conclusion}

Thermal analysis of the substrate structural materials is analyzed in detail during plasma disruptions. Tile and coating materials are essential to protect the substrate structure materials during the disruption. The disruption scenario and parameters are key factors in determining the required minimum thickness of coating and tile materials to protest the struct ire underneath. Beryllium coating in general protects the substrate material better than tungsten for the same disruption conditions. Adequate substrate performance for a tile design should be evaluated near the end-of-life of the tile material. Coating thickness should be minimized to reduce potential probiems such as radioactivity, toxicity, and plasma contamination. 


\section{References}

[1] A. Hassanein, ASME, 88-WA/NE-2.

[2] J. Van der Laan et al., to be publisted in Fusion Technology.

[3] A. Hassanein, Fusion Technology Vol. 19 (1991) 1789.

[4] A. Hassane in, J. Nucl. Mater. 122 \& 12 (1984) 1453.

[5] A. Hassane in and D. Ehst, to be published.

[6] W. Wolfer and A. Hassanein, J. Nucl. Mater. 111 \& 112 (1982) 560.

[7] A. Hassanein, Fusion Technology Vol. 15 (1989) 513. 


\section{Figure Captions}

Fig. 1. The effect of the thermal disruption time on the substrate surface temperature.

Fig. 2. Stainless steel substrate surface temperature for $0.5 \mathrm{~mm}$ tungsten coating.

Fig. 3. The effect of the current disruption time on the substrate surface temperature.

Fig. 4. Response of the substrate to a separate and to a combined disruptions.

Fig. 5. The effect of different coating materials on the substrate surface temperature.

Fi.6. Tile surface temperature rise for a two-phase disruption scenario.

Fig. 7. The effect of the thermal quench time on the substrate surface temperature.

Fig. 8. Substrate surface temperature at both the beginning and at the endof -life. 


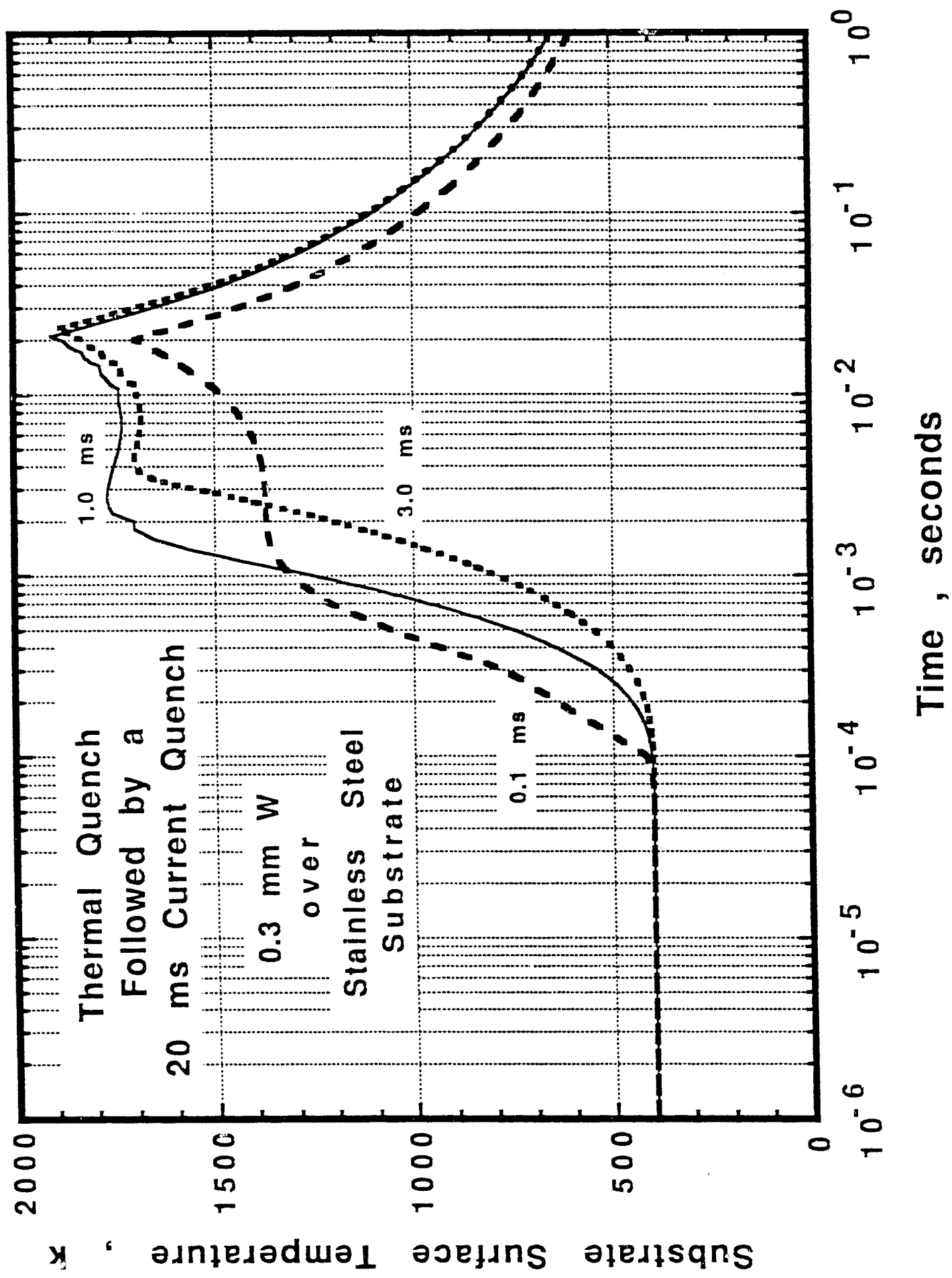




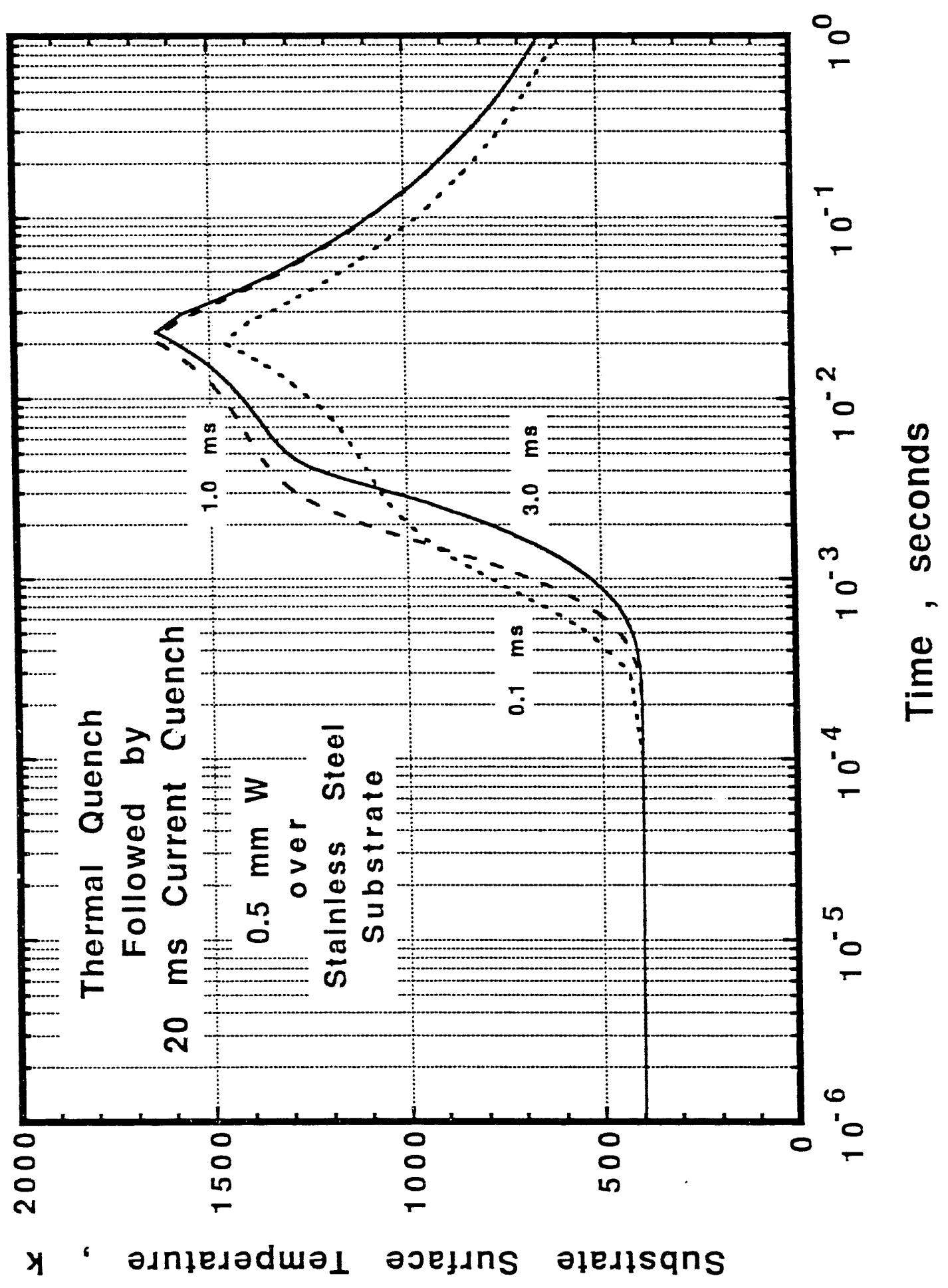


$\frac{0}{5}$

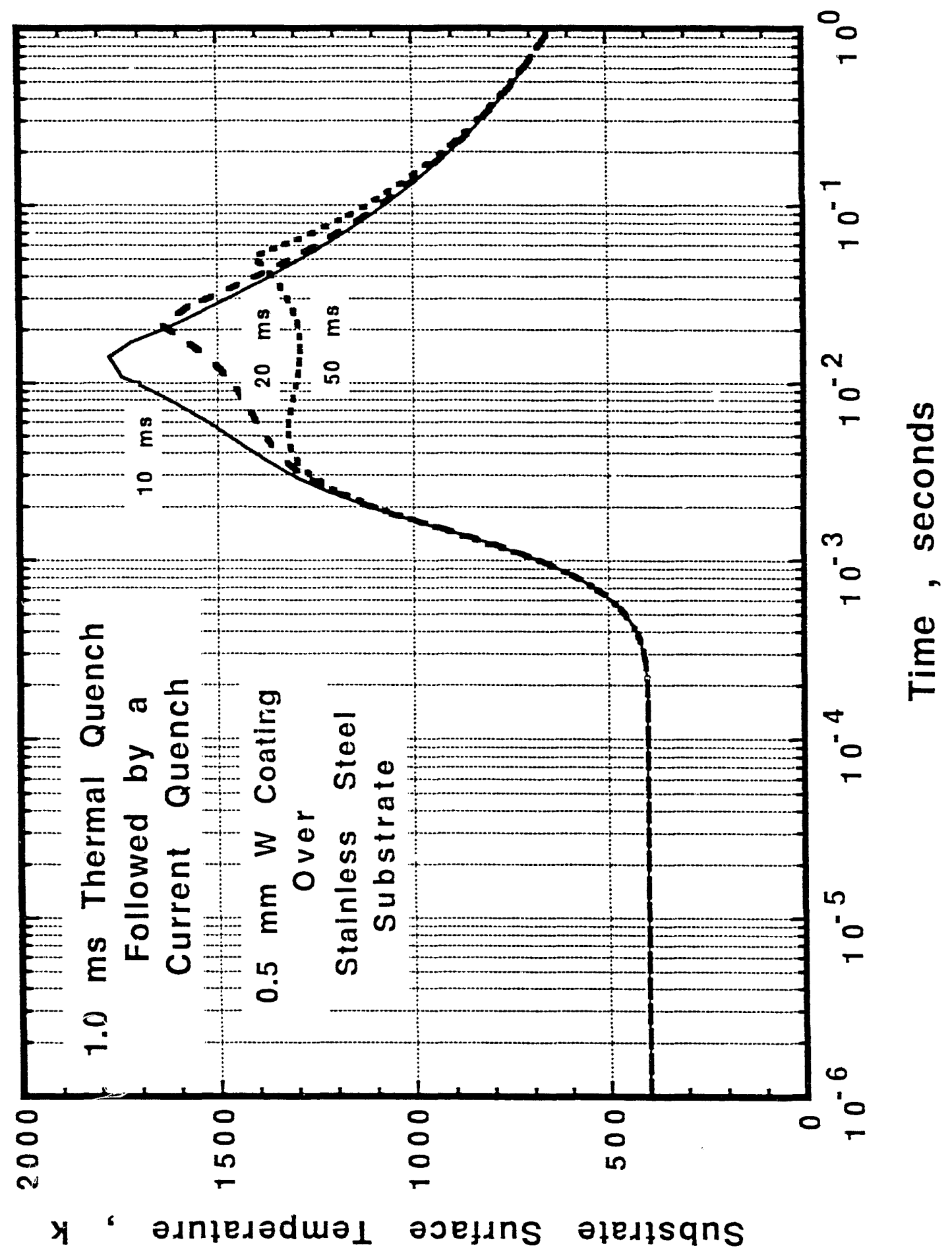




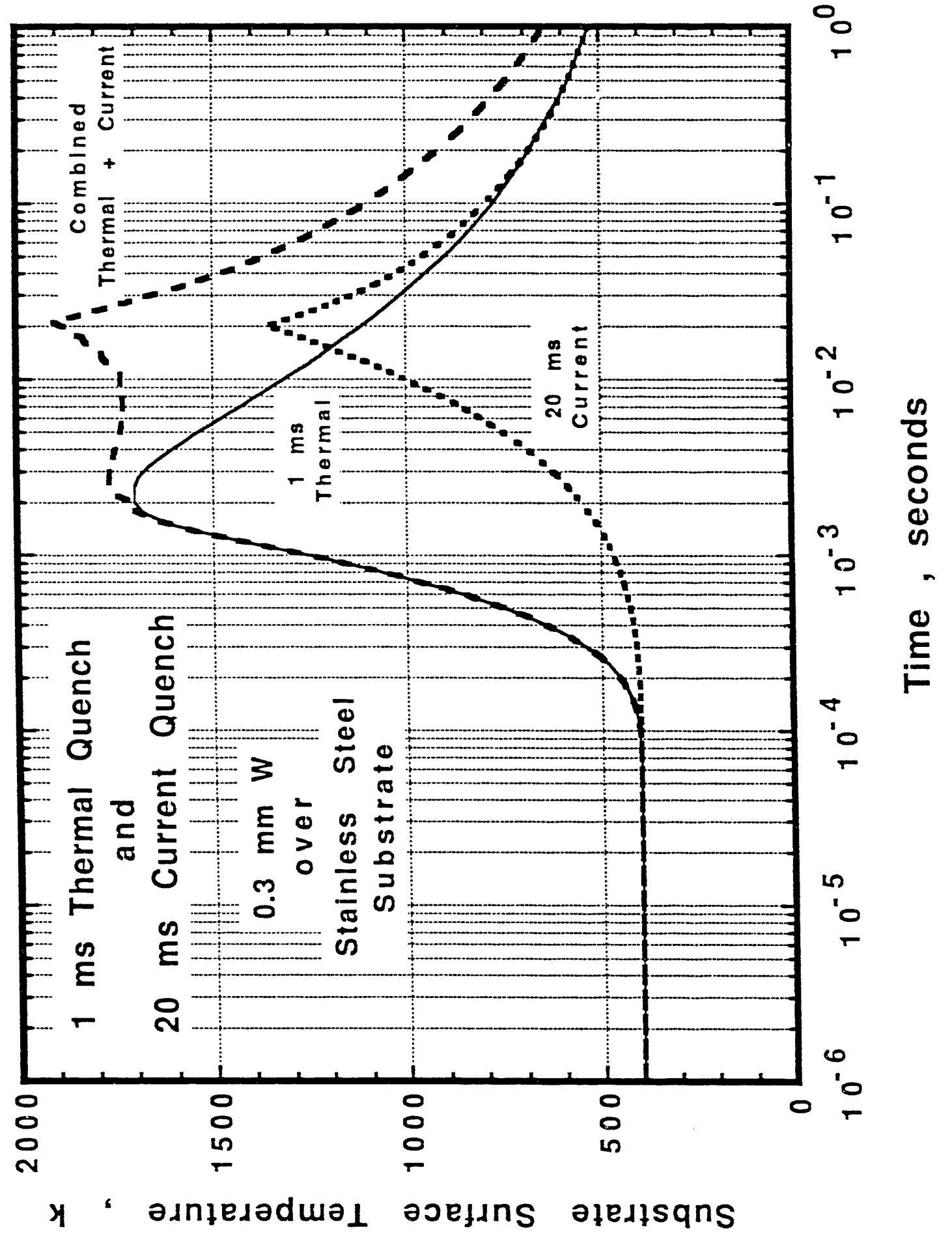




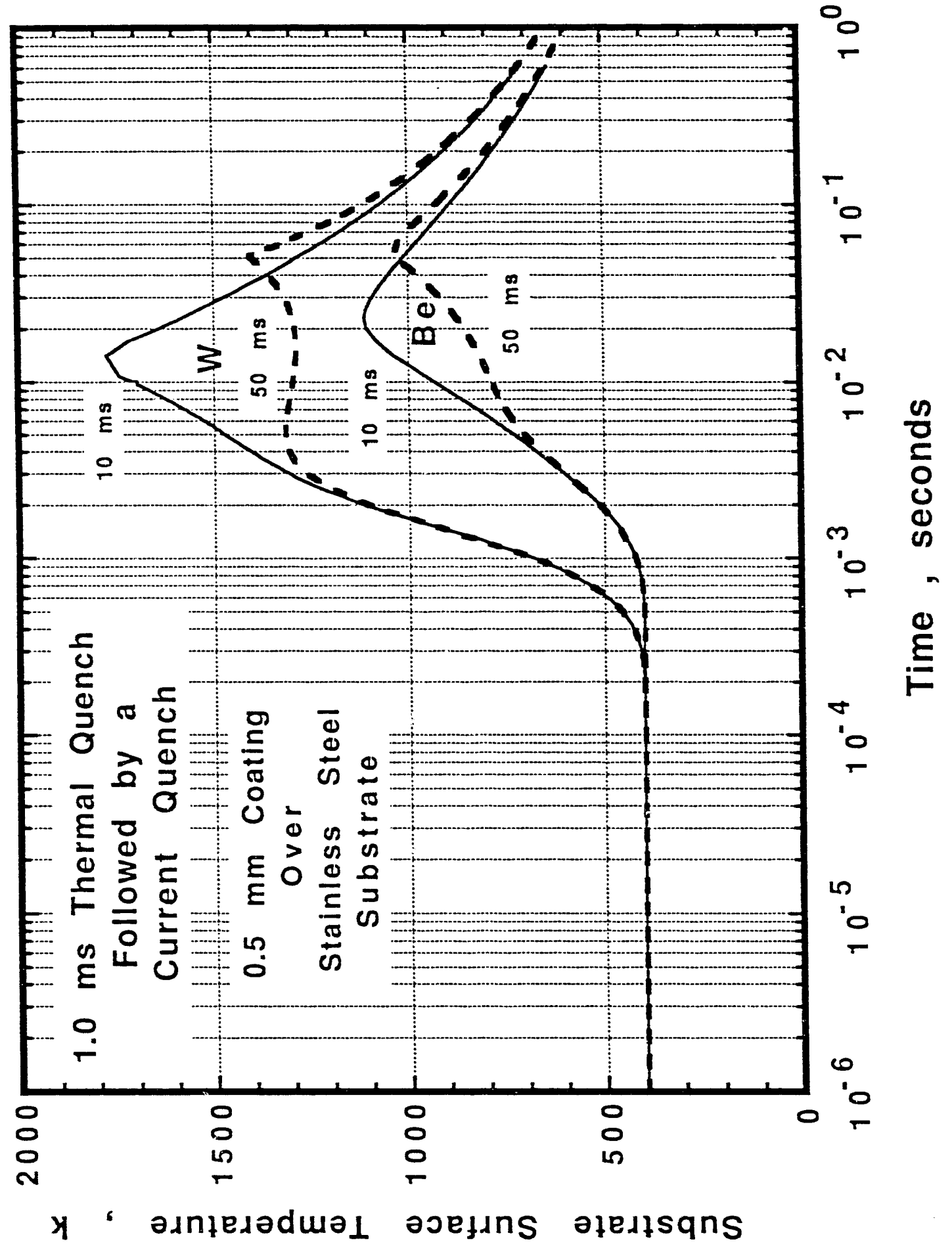




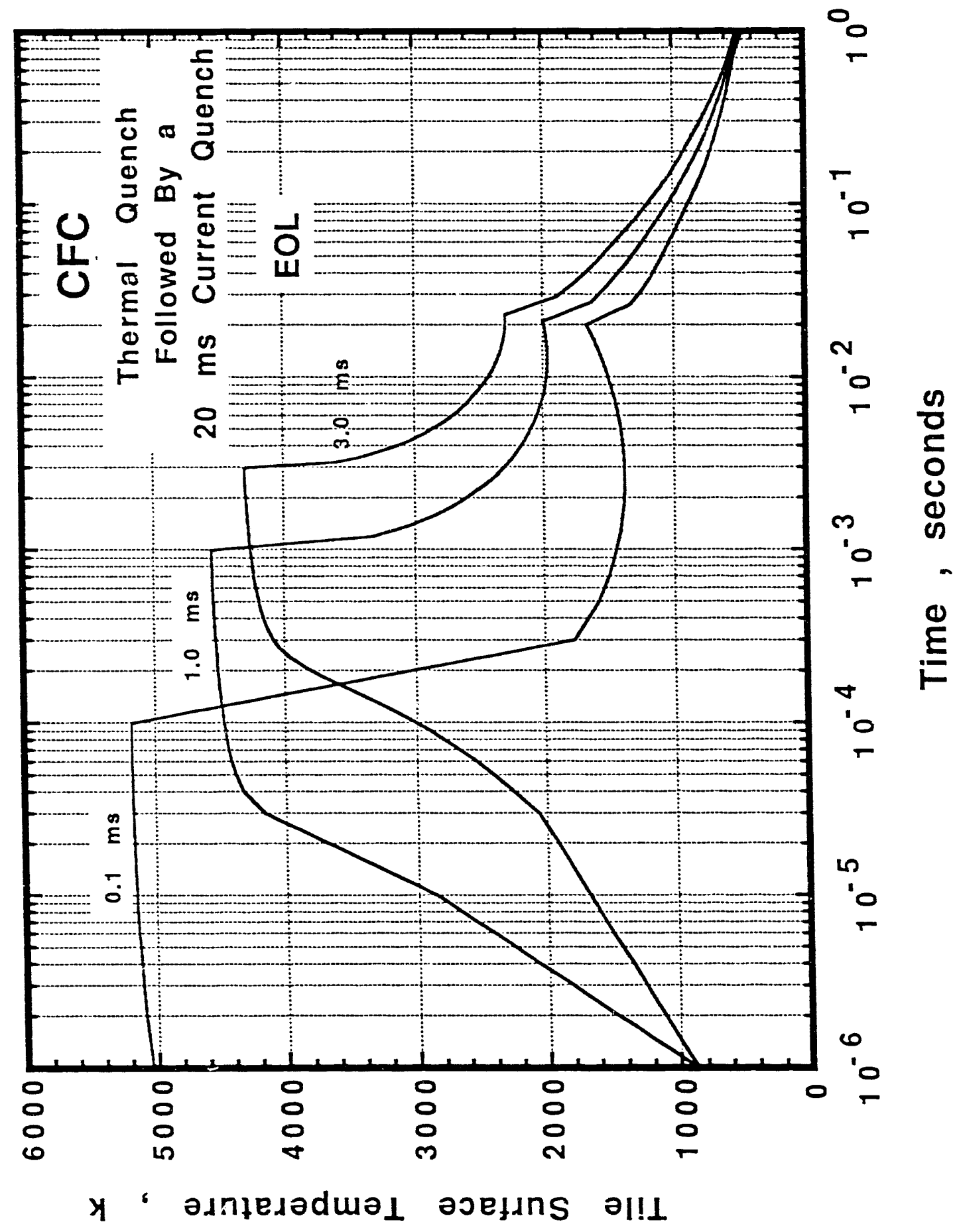



3.

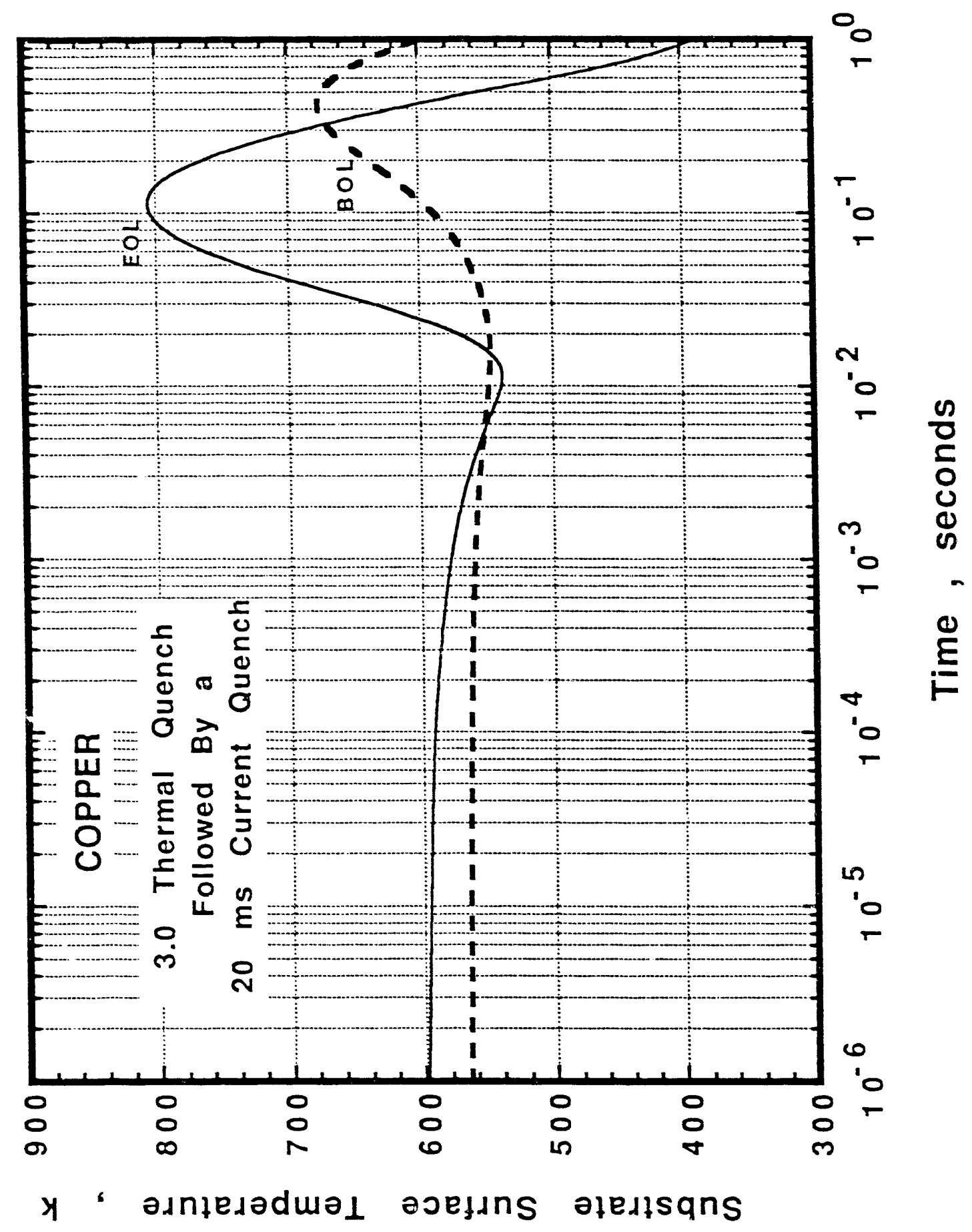



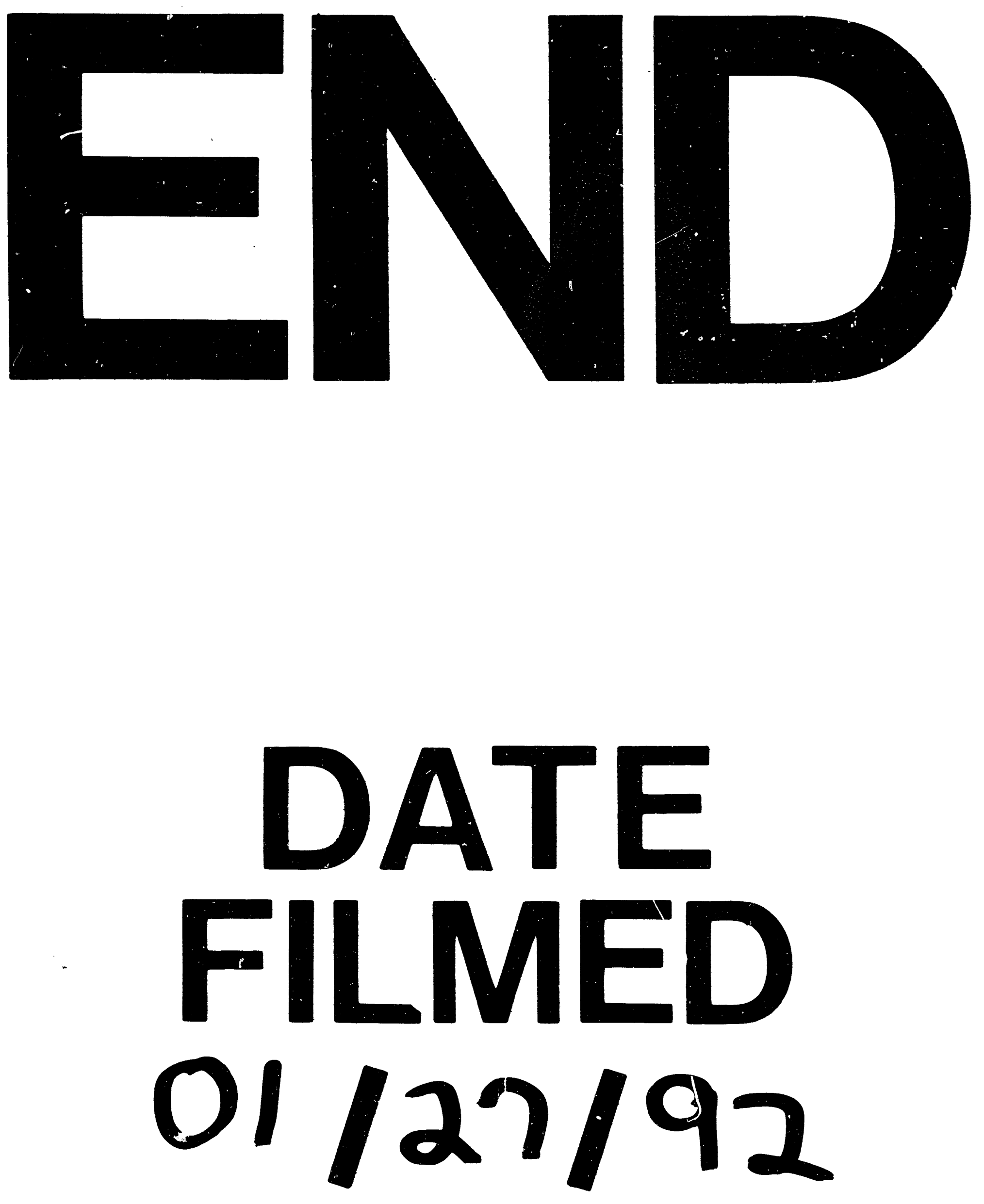
